Artikel Penelitian

\title{
Profil FTIR Minyak Ikan dan Lemak Babi serta Perbandingannya sebagai Dasar Penentuan Autentifikasi Halal
}

\author{
Dewi Sinta Megawati*, Begum Fauziyah, Siti Maimunah, Abdul Wafi \\ Jurusan Farmasi, Fakultas Kedokteran dan Ilmu Kesehatan, Universitas Islam Negeri Maulana Malik Ibrahim, Malang, \\ Indonesia, 65144
}

INFO ARTIKEL

\section{Riwayat Artikel}

Diterima 1 Juni 2020

Direvisi 9 Juni 2020

Tersedia online 29 Juni 2020

\footnotetext{
* Email penulis korespondensi: dewisinta@farmasi.uin-malang.ac.id
}

\section{ABSTRAK}

Research has been conducted on the determination of tuna oil and lard spectra using FTIR. This research aims to determine the IR spectra profile of lard and tuna oil and to compare both spectra profiles. Profile and comparison of lard and tuna oil IR spectra useful to determine whether an ingredient or a product contaminated with lard. The fatty acid profile of lard by FTIR analysis showed a significant difference in the absorption patterns of the spectra, especially at 3010-3000, 16801600 , and $968-966 \mathrm{~cm}^{-1}$ wavenumbers which represented the different composition and type of fatty acids in the lard and tuna oil. The absorption patterns at 3007 and $1653 \mathrm{~cm}^{-1}$ regions (double bond $\mathrm{C}=\mathrm{C}$ cis) for tuna oil showed relatively high peaks if it is compared to lard samples because of the percentage of MUFA fatty acids (oleic acid) in tuna oil was much higher.

Keywords: Lard, tuna oil, IR spectra of lard, IR spectra of tuna oil

Telah dilakukan penelitian mengenai penentuan spektra minyak ikan tuna dan lemak babi dengan menggunakan FTIR. Penelitian ini bertujuan untuk mengetahui profil spektra IR dari lemak babi dan minyak ikan tuna serta membandingkan kedua profil spektranya. Profil dan perbandingan spektra IR lemak babi dan minyak ikan tuna dapat digunakan sebagai dasar penentuan apakah suatu bahan atau produk terkontaminasi lemak babi. Profil asam lemak babi hasil analisis FTIR menunjukkan adanya perbedaan yang cukup signifikan pada pola-pola penyerapan spektra, khususnya pada bilangan gelombang 3010-3000, 1680-1600 dan 968-966 cm-1 yang merepresentasikan perbedaan komposisi dan jenis asam lemak pada sampel lemak babi dan minyak ikan tuna. Pola serapan pada bilangan gelombang 3007 dan $1653 \mathrm{~cm}^{-1}$ (ikatan rangkap $\mathrm{C}=\mathrm{C}$ cis) untuk sampel minyak ikan tuna menunjukkan puncak yang relatif tinggi jika dibandingkan dengan sampel lemak babi karena persentase asam lemak MUFA (asam oleat) pada minyak ikan tuna jauh lebih tinggi.

Kata kunci: Lemak babi, minyak ikan tuna, spektra IR lemak babi, spektra IR minyak ikan 


\section{Pendahuluan}

Makanan dan minuman merupakan kebutuhan dasar bagi manusia untuk melangsungkan hidupnya. Makanan dan minuman yang dikonsumsi berperan penting dalam menjamin kualitas kesehatan manusia. Dengan demikian, penting bagi manusia untuk memperhatikan kualitas makanan dan minuman yang dikonsumsi agar tidak mengganggu kesehatan. Dalam rangka menjamin kesehatan manusia, Badan Kesehatan Dunia (WHO) dan Organisasi Pangan dan Pertanian (FAO) saat ini memberikan penekanan bagi seluruh negara agar memperkuat sistem keamanan pangan. Hal ini juga dilatarbelakangi dengan semakin berkembangnya jumlah produsen dan jenis makanan dalam kurun waktu yang cepat. Seiring dengan perkembangan tersebut, isu yang muncul dan berkembang dalam hal bahan serta kualitas makanan juga meningkat.

Di Indonesia yang mayoritas penduduknya memeluk agama Islam, isu tentang keamanan pangan yang sangat mengemuka adalah adanya tambahan penggunaan bahan yang berbahaya bagi kesehatan dan bahan non halal dalam makanan dan minuman yang beredar di masyarakat. Bahan tambahan pangan menjadi perhatian karena ada kemungkinan bahan dasar yang digunakan berasal dari salah satu bahan yang diharamkan [1]. Bahan non halal yang isu penggunaannya mengemuka dalam makanan antara lain bagian dari babi, bagian dari tikus dan bekicot. Isu penggunaan bahan non halal terdapat pada produk sosis, nugget, bakso, kuah bakso, mie ayam dan beberapa produk lain seperti minyak ikan. Minyak ikan merupakan minyak yang harganya lebih mahal dibandingkan minyak hewan lain seperti kambing, ayam, sapi dan babi. Oleh karena itu, minyak ikan dipalsukan untuk meningkatkan keuntungan ekonomi [2].

Meskipun masalah kehalalan pangan merupakan isu yang sering menjadi polemik di tengah masyarakat Indonesia, solusi yang memiliki signifikansi yang tinggi dalam menyelesaikan permasalahan tersebut belum tepat. Sejauh ini, Pemerintah Indonesia melalui SK bersama (LPPOM MUI, DEPAG dan BPOM Depkes) telah mencanangkan Sistem Jaminan Halal yang diwujudkan dalam bentuk Sertifikasi Halal bagi setiap produsen produk pangan. Namun demikian, implementasi sistem jaminan halal ini dalam kenyataannya masih menemukan berbagai kendala, salah satunya adalah ketiadaan metode yang efektif untuk menganalisis substansi produk pangan sehingga bisa menjamin kehalalan dari produk pangan tersebut [3].

Berlatarbelakang permasalahan tersebut, dilakukan penelitian mengenai identifikasi lemak/minyak ikan dan bahan non halal yaitu lemak babi dengan menggunakan FTIR (Fourier Transform Infrared). FTIR merupakan salah satu metode analisis yang dapat memberikan hasil yang cepat dan akurat. Instrumentasi ini dapat menganalisis tanpa merusak sampel dan hanya dibutuhkan preparasi sampel yang sederhana [4]. FTIR dapat menganalisis kandungan lemak babi yang sangat rendah. Hasil yang diperoleh menunjukkan bahwa FTIR sangat berpotensi untuk digunakan sebagai alat untuk mendeteksi lemak babi secara cepat dengan hasil yang konsisten [3]. Profil atau pola spektrum IR dari lemak babi yang diperoleh akan dibandingkan dengan pola spektrum IR minyak ikan. Dalam hal ini, ikan yang digunakan sebagai sampel adalah ikan tuna. Profil spektra FTIR lemak babi dan minyak ikan akan bermanfaat sebagai dasar penentuan kehalalan suatu produk sampel minyak ikan yang telah terkontaminasi lemak babi atau tidak melalui perbandingan spektra dari kedua produk tersebut.

\section{Bahan dan Metode}

\subsection{Bahan}

Bahan yang digunakan meliputi sampel jaringan lemak hewani ikan tuna dan babi. Adapun bahan lain yang digunakan adalah n-heksana (p.a) sebagai pelarut untuk ekstraksi lemak/minyak (Merck) dan $\mathrm{Na}_{2} \mathrm{SO}_{4}$ untuk memurnikan lemak.

\subsection{Preparasi Sampel}

Bahan baku yang digunakan berupa ikan tuna yang diambil dari pasar ikan yang terletak di Merjosari, Malang. Ikan dipotong-potong sehingga menjadi potongan kecil dengan berat $100 \mathrm{gr} \mathrm{yang}$ bertujuan untuk memudahkan proses ekstraksi, sedangkan sampel lemak babi diambil dari rumah pemotongan hewan (RPH) Malang.

\subsection{Ekstraksi Minyak Ikan dengan Metode Soxhlet}

Sebanyak $100 \mathrm{gr}$ daging ikan tuna diiris kecil-kecil dan dimasukkan ke dalam cawan porselin. Selanjutnya, sampel dimasukkan ke dalam oven pada suhu $100^{\circ} \mathrm{C}$ dan dibiarkan selama 6 jam untuk menghilangkan kadar airnya. Setelah itu, sampel daging ikan ditimbang dan dimasukkan ke dalam kertas saring atau kantung ekstraksi. Kertas saring yang berisi sampel dimasukkan ke dalam ekstraktor soxhlet. Pelarut n-heksana sebanyak $250 \mathrm{~mL}$ dimasukkan ke dalam labu alas bulat. Sebelum digunakan, labu alas bulat dipanaskan dalam oven dan ditimbang setelah didinginkan dalam desikator. Sampel diekstrak dengan pelarut tersebut hingga minimal 5 kali sirkulasi. Kemudian, labu alas bulat dikeringkan dalam oven pada suhu $105^{\circ} \mathrm{C}$ selama 30 menit hingga aroma n-heksana tidak tercium. Minyak yang diperoleh dikumpulkan dan selanjutnya dianalisis menggunakan spektroskopi FTIR. 


\subsection{Ekstraksi Minyak Babi dengan Metode Oven}

Dua gram sampel jaringan lemak babi dicuci, diiris kecil-kecil dan dimasukkan ke dalam gelas kimia. Selanjutnya, sampel dimasukkan ke dalam oven pada suhu $75^{\circ} \mathrm{C}$ dan dibiarkan selama 6 jam hingga jaringan lemaknya mencair. Lemak padat yang sudah mencair dipisahkan dan dimasukkan ke dalam corong pisah untuk selanjutnya dimurnikan dengan menambahkan pereaksi $n$-heksana. Lemak yang sudah dimurnikan disaring dalam kertas saring yang sudah ditambahkan natrium sulfat $\left(\mathrm{Na}_{2} \mathrm{SO}_{4}\right)$ untuk mengikat air yang masih ada pada lapisan lemak. Hasil ekstraksi ditimbang dan ditentukan persen rendemennya [5].

\subsection{Analisis FTIR Lemak Ikan dan Babi}

Sampel lemak yang telah disaring dan dimurnikan diteteskan pada salah satu permukaan sel $\mathrm{KBr}$. Diantara kedua sel $\mathrm{KBr}$ diberi pembatas berupa politetrafluoroetilen (PTFE) untuk menghasilkan ketebalan lapisan lemak $0,1 \mathrm{~mm}$. Sel bagian lainnya ditangkupkan hingga terbentuk lapisan tipis lemak. Scanning dilakukan dengan kisaran panjang gelombang 4000$650 \mathrm{~cm}^{-1}$ dengan resolusi $4 \mathrm{~cm}^{-1}$. Hasil scanning direkam dan dianalisis lebih lanjut.

\section{Hasil dan Pembahasan}

\subsection{Ekstraksi Minyak Ikan}

Prinsip dari proses ini adalah ekstraksi dengan melarutkan minyak dalam pelarut minyak dan lemak. Pelarut minyak atau lemak yang digunakan dalam penelitian ini adalah $n$-heksana dengan titik didih $60-80^{\circ} \mathrm{C}$. Minyak ikan mengandung sejumlah asam lemak, baik jenuh maupun tidak jenuh, yang bersifat non-polar. Oleh karena itu, digunakan pelarut $n$ heksana yang juga bersifat non-polar. Sebagaimana prinsip "like dissolve like" yaitu senyawa polar hanya dapat larut dalam pelarut polar dan senyawa nonpolar hanya dapat larut dalam pelarut nonpolar.

Sampel yang digunakan berupa daging ikan tuna sebanyak $100 \mathrm{gr}$ berwujud padat sehingga metode ekstraksi yang digunakan adalah metode soxhlet. Menurut Khamidinal [6], ekstraksi padat-cair digunakan untuk memisahkan analit yang terdapat pada padatan menggunakan pelarut organik. Padatan yang akan diekstrak dipreparasi terlebih dahulu dengan cara ditumbuk atau dipotong sehingga berukuran lebih kecil. Kemudian, padatan yang telah halus dibungkus dengan kertas saring, ekstraksi dilakukan dengan memanaskan pelarut organik sampai semua analit terekstrak. Ekstraksi dengan soxhlet memberikan hasil ekstrak yang lebih tinggi karena dengan cara ini digunakan pemanasan yang diduga memperbaiki kelarutan ekstrak. Perlu diperhatikan bahwa jumlah pelarut menguap atau hilang tidak boleh lebih dari $5 \%$, apabila lebih, seluruh sistem solvent ekstraksi perlu diteliti lagi. Dibandingkan dengan cara maserasi, ekstraksi dengan soxhlet memberikan hasil ekstrak yang lebih tinggi.

Labu alas bulat yang digunakan sebelumnya dioven terlebih dahulu. Hal ini bertujuan untuk menghilangkan kadar air dan lemak yang menempel pada labu. Setelah dioven, labu alas bulat disimpan dalam desikator yang berisi silika gel. Silika gel berfungsi sebagai penyerap air dan menyeimbangkan suhu labu agar dingin ketika penimbangan. Setelah proses ekstraksi soxhlet selesai, maka labu alas bulat harus dikeringkan di dalam oven $105^{\circ} \mathrm{C}$ selama 30 menit hingga aroma nheksana tidak tercium. Proses ektraksi daging ikan tuna menggunakan metode soxhlet ditunjukkan sebagaimana Gambar 1(a). Ekstrak minyak ikan yang diperoleh berwarna kuning bening (Gambar 1(b)) dengan berat 0,5 gr (rendemen 0,5\%).

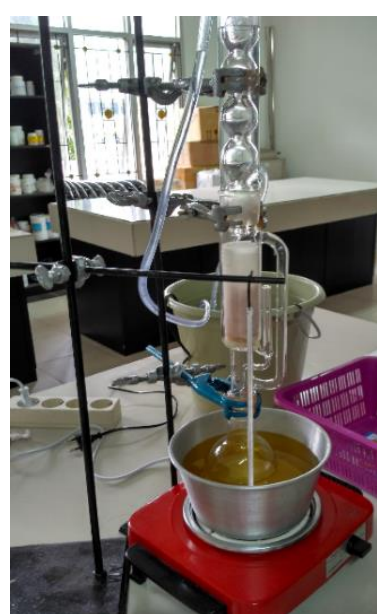

(a)

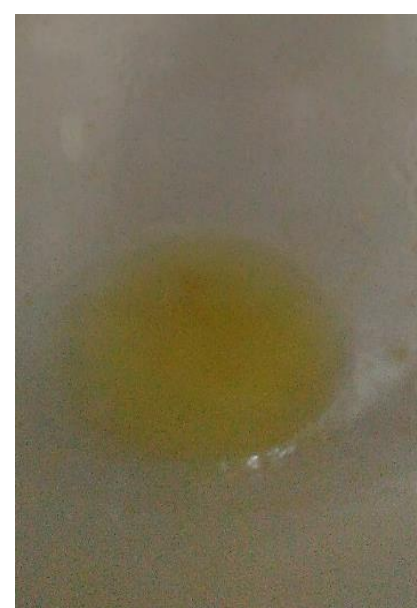

(b)

Gambar 1. (a) Ekstraksi daging ikan tuna, dan (b) Ekstrak minyak ikan. 


\subsection{Ekstraksi Lemak Babi}

Ekstraksi lemak babi dilakukan menggunakan metode ekstraksi cair-cair karena sampel yang diekstrak berwujud cair. Ekstraksi cair-cair merupakan suatu pemisahan yang didasarkan pada perbedaan kelarutan komponen dua pelarut yang tidak saling bercampur. Alat yang digunakan adalah alat yang sederhana yaitu corong pisah. Pelarut yang digunakan adalah $n$-heksana karena lemak larut dalam pelarut organik, dalam hal ini karena lemak merupakan senyawa trigliserida yang bersifat non-polar, maka pelarut yang digunakan juga bersifat non-polar. Sebelum sampel diekstrak, sampel lemak dipanaskan dalam oven terlebih dahulu dengan tujuan untuk menguapkan kadar airnya dan juga berfungsi mencairkan lemak babi yang berwujud padat. Ekstrak lemak babi yang dihasilkan berwarna putih bening (Gambar 2) dengan berat $51,9 \mathrm{gr}$ dengan rendemen sebesar $65,5 \%$.

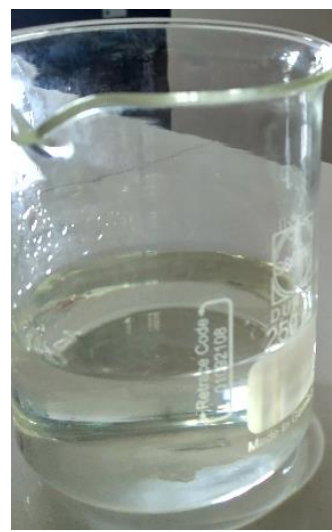

Gambar 2. Ekstrak lemak babi.

\subsection{Analisis Data Pola Spektra IR Minyak Ikan Tuna}

Analisis hasil ekstraksi minyak ikan tuna menggunakan spektroskopi FTIR disajikan pada Gambar 3 dan hasil analisis data pada Tabel 1. Berdasarkan Gambar 3, dapat diperkirakan bahwa senyawa yang dianalisis memiliki gugus karbonil ($\mathrm{C}=0$ ) sebab terdapat pita kuat dengan intensitas tajam pada bilangan gelombang $1746 \mathrm{~cm}^{-1}$ dengan overtone lemahnya pada bilangan gelombang $3473 \mathrm{~cm}^{-1}$ yang menunjukkan adanya vibrasi rentangan gugus karbonil. Adanya serapan kuat pada bilangan gelombang $1150 \mathrm{~cm}^{-1}$ menegaskan bahwa gugus karbonil yang teridentifikasi merupakan gugus ester. Gugus ester ini memungkinkan karena senyawa hasil ekstraksi minyak ikan tuna merupakan trigliserida yang juga merupakan senyawa ester.

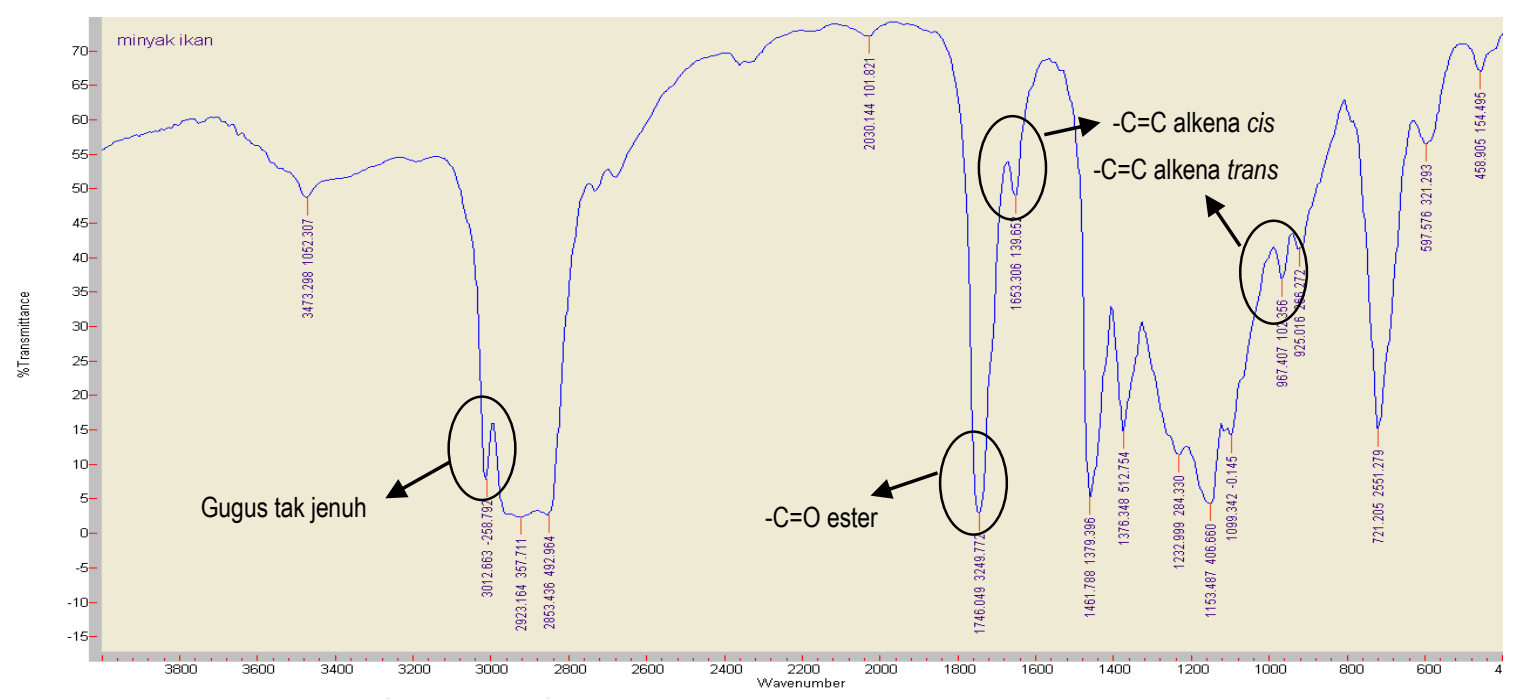

Gambar 3. Spektra IR hasil ekstraksi minyak ikan tuna.

Pita C-H tajam pada bilangan gelombang $3012 \mathrm{~cm}^{-1}$ menunjukkan adanya gugus tak jenuh $(=\mathrm{C}-\mathrm{H})$. Hal ini diperkuat oleh pita lemah tetapi tajam dekat bilangan gelombang $1653 \mathrm{~cm}^{-1}$ yang disebabkan oleh gugus $C=C$. Adanya serapan kuat pada bilangan gelombang 2923 dan $2853 \mathrm{~cm}^{-1}$ merupakan karakteristik serapan gugus alkil oleh vibrasi rentangan $\mathrm{C}_{\mathrm{sp}}{ }^{3}-\mathrm{H}$, diperkuat oleh adanya serapan pada bilangan gelombang $1461 \mathrm{~cm}^{-1}$ yang menunjukkan vibrasi bengkokan $\mathrm{C}-\mathrm{H}$ gugus metilen (- $\mathrm{CH}_{2}-$ ). Berdasarkan database SDBS (Spectral Database) spektra IR dari asam oleat pada Gambar 4, dapat dilihat 
bahwa pola spektra minyak ikan menyerupai pola spektra IR dari asam oleat yang merupakan asam lemak tak jenuh yang mengandung satu ikatan rangkap atau termasuk dalam golongan monounsaturated fatty acid (MUFA).

Tabel 1. Analisis Data Spektra IR Hasil Ekstraksi Minyak Ikan Tuna

\begin{tabular}{cc}
\hline Bilangan Gelombang $\left(\mathbf{c m}^{-1}\right)$ & Gugus Fungsi \\
\hline 1746 & $-\mathrm{C}=\mathrm{O}$ karbonil \\
1150 & $-\mathrm{C}-\mathrm{O}$ ester \\
3012 & $=\mathrm{C}-\mathrm{H}$ (gugus tak jenuh) \\
1653 & $-\mathrm{C}=\mathrm{C}$ alkena \\
967 & $-\mathrm{C}=\mathrm{C}$ alkena trans \\
2923 dan 2853 & $-\mathrm{Csp}^{3}-\mathrm{H}$ \\
1461 & $-\mathrm{CH}_{2-}$ \\
\hline
\end{tabular}

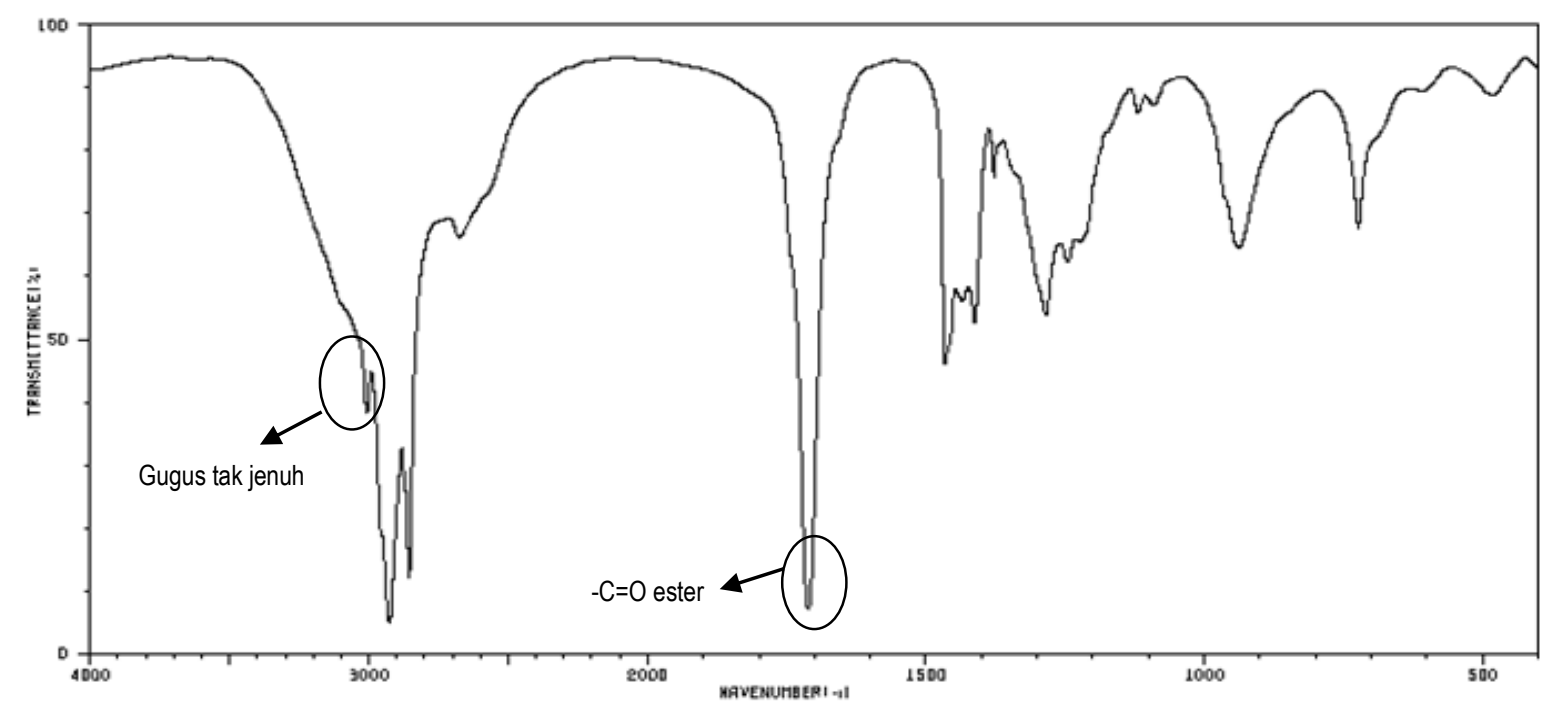

Gambar 4. Spektra IR berdasarkan database SDBS asam oleat.

\subsection{Analisis Data Pola Spektra IR Lemak Babi}

Analisis hasil ekstraksi lemak babi menggunakan spektroskopi FTIR disajikan pada Gambar 5 dan hasil analisis data pada Tabel 2. Berdasarkan Gambar 5, dapat diperkirakan bahwa senyawa yang dianalisis memiliki gugus karbonil (-C=0) sebab terdapat pita kuat dengan intensitas tajam pada bilangan gelombang $1745 \mathrm{~cm}^{-1}$ dengan overtone lemahnya pada bilangan gelombang $3472 \mathrm{~cm}^{-1}$ yang menunjukkan adanya vibrasi rentangan gugus karbonil. Adanya serapan kuat pada bilangang gelombang $1162 \mathrm{~cm}^{-1}$ menegaskan bahwa gugus karbonil yang teridentifikasi merupakan gugus ester. Gugus ester ini memungkinkan karena senyawa hasil ekstraksi lemak babi merupakan trigliserida yang juga merupakan senyawa ester.

Tabel 2. Analisis Data Spektra IR Hasil Ekstraksi Lemak Babi

\begin{tabular}{cc}
\hline Bilangan Gelombang $\left(\mathbf{c m}^{-1}\right)$ & Gugus Fungsi \\
\hline 1745 & $-\mathrm{C}=\mathrm{O}$ karbonil \\
1162 & $-\mathrm{C}-\mathrm{O}$ ester \\
3007 & $=\mathrm{C}-\mathrm{H}$ (gugus tak jenuh) \\
1654 & $-\mathrm{C}=\mathrm{C}$ alkena cis \\
967 & $-\mathrm{C}=\mathrm{C}$ alkena trans \\
2925 dan 2854 & $-\mathrm{C}_{\text {sp }}{ }^{3}-\mathrm{H}$ \\
1462 & $-\mathrm{CH}_{2-}$ \\
\hline
\end{tabular}

Pita C-H tajam pada bilangan gelombang $3007 \mathrm{~cm}^{-1}$ menunjukkan adanya gugus tak jenuh. Hal ini diperkuat oleh pita lemah tetapi tajam dekat bilangan gelombang $1654 \mathrm{~cm}^{-1}$ yang disebabkan oleh gugus $\mathrm{C}=\mathrm{C}$. Adanya serapan kuat pada bilangan gelombang 2925 dan $2854 \mathrm{~cm}^{-1}$ merupakan karakteristik serapan gugus alkil oleh vibrasi rentangan $\mathrm{Csp}^{3}-\mathrm{H}$, diperkuat oleh adanya serapan pada bilangan gelombang $1462 \mathrm{~cm}^{-1}$ yang menunjukkan vibrasi bengkokan $\mathrm{C}-\mathrm{H}$ gugus metilen (- $\mathrm{CH}_{2-}$ ). Berdasarkan database SDBS (Spectral Database) spektra IR dari asam linoleat sebagaimana Gambar 6 , 
dapat dilihat bahwa pola spektra lemak babi menyerupai pola spektra IR dari asam linoleat yang merupakan asam lemak tak jenuh yang mengandung dua ikatan rangkap atau yang termasuk dalam golongan polyunsaturated fatty acids (PUFA).

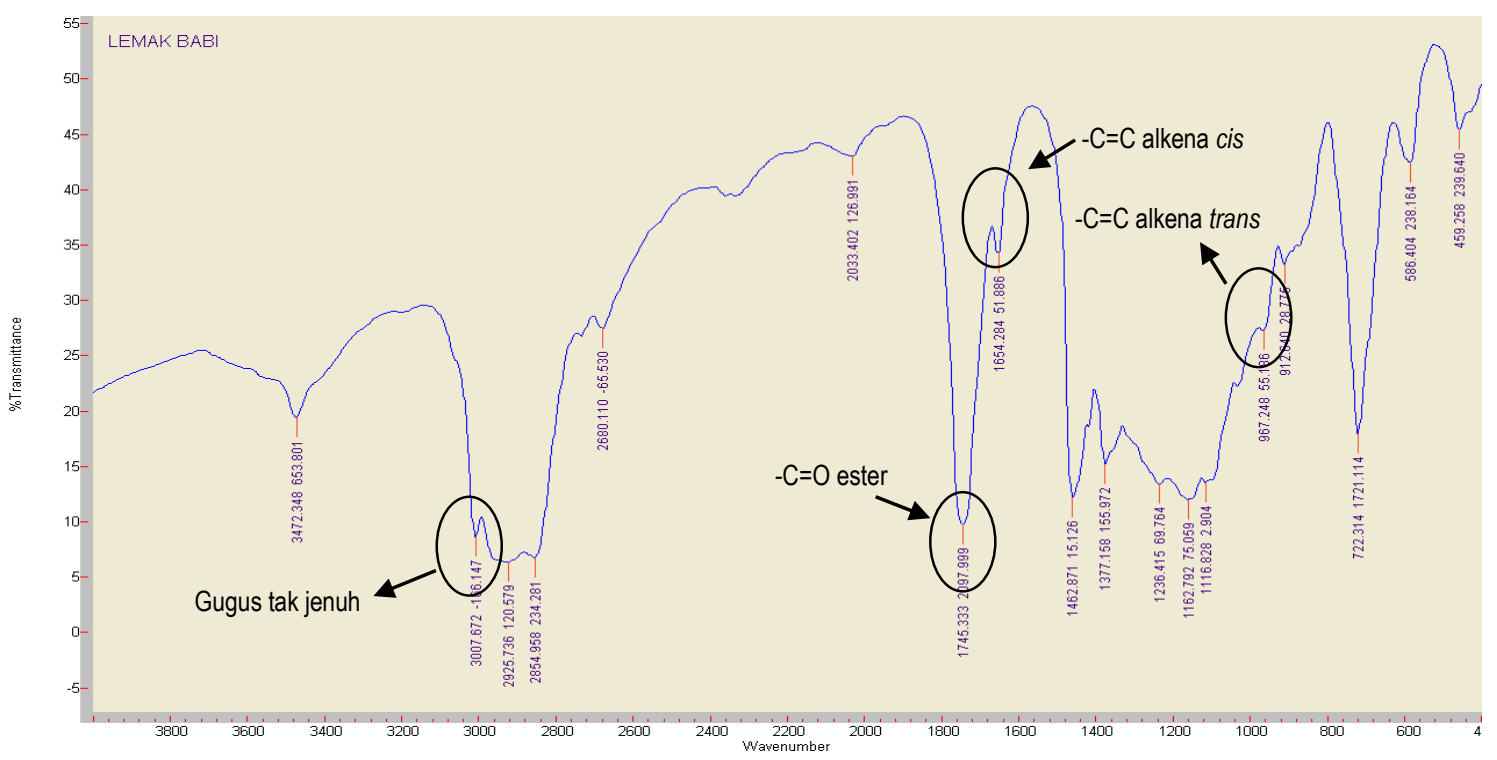

Gambar 5. Spektra IR hasil ekstraksi lemak babi.

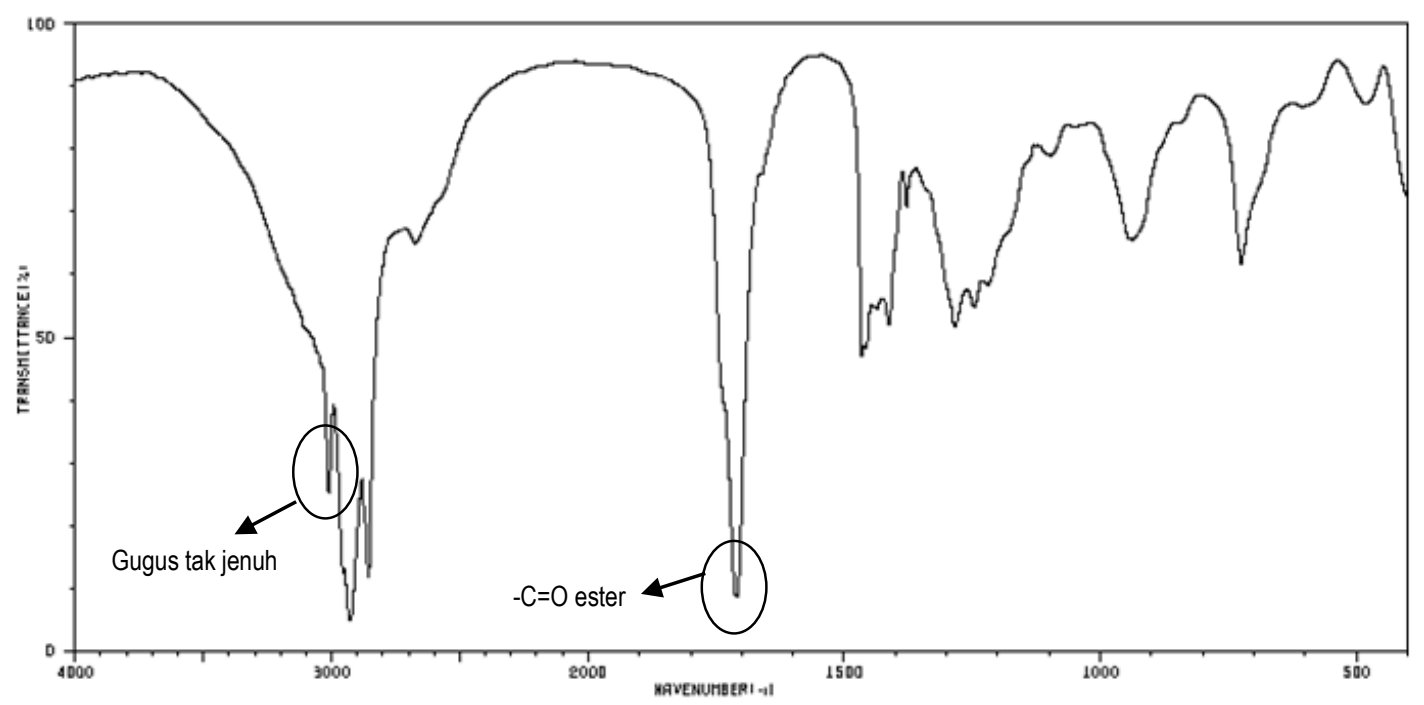

Gambar 6. Spektra IR berdasarkan database SDBS asam linoleat.

\subsection{Analisis Data Pola Spektra IR Gabungan Lemak Babi dan Minyak Ikan}

Analisis perbandingan data pola spektra IR antara lemak babi dan minyak ikan disajikan pada Gambar 7. Berdasarkan Gambar 7, terlihat ada perbedaan yang cukup signifikan pada pola-pola penyerapan spektra, khususnya pada bilangan gelombang 3010-3000, 1680-1600 dan 968-966 cm-1. Menurut standar yang telah ditetapkan oleh AOCS (American Oils Chemistry Standard), rentang frekuensi IR pada bilangan gelombang 975-965 $\mathrm{cm}^{-1}$ merupakan dasar dari metode kuantisasi asam lemak trans dalam sampel lemak/minyak [7].

Pada sampel minyak ikan, pola serapan yang muncul pada bilangan gelombang 3007 dan $1653 \mathrm{~cm}^{-1}$ menunjukkan puncak yang relatif tinggi jika dibandingkan dengan sampel lemak babi. Tingginya puncak serapan untuk minyak ikan pada daerah ini merepresentasikan streching vibration dari ikatan rangkap $\mathrm{C}=\mathrm{C}$ cis. Menurut De Man [8], minyak ikan memiliki tiga jenis asam lemak yaitu asam lemak jenuh yaitu asam lemak yang tidak mempunyai ikatan rangkap pada rantai karbonnya, seperti palmitoleat. Asam lemak tidak jenuh tunggal (MUFA) yaitu asam lemak yang mempunyai satu ikatan rangkap pada rantai karbonnya, seperti asam oleat. Asam lemak tidak jenuh ganda (PUFA) yaitu asam lemak yang mempunyai lebih dari satu ikatan rangkap pada rantai karbonnya, seperti linoleat, asam eikosapentanoat (EPA) dan asam dokosaheksanoat (DHA). 
Gabungan konfigurasi atom karbon DHA dan EPA dikenal sebagai omega-3. Penelitian yang dilakukan oleh Defandi [9] tentang limbah ikan tuna menyatakan bahwa asam lemak oleat (MUFA) yang dihasilkan pada kulit, kepala dan tulang ikan berturut-turut sebesar 40,04;61,11 dan $64,58 \%$. Senyawa asam oleat dan struktur senyawa trigliseridanya ditunjukkan pada Gambar 8.

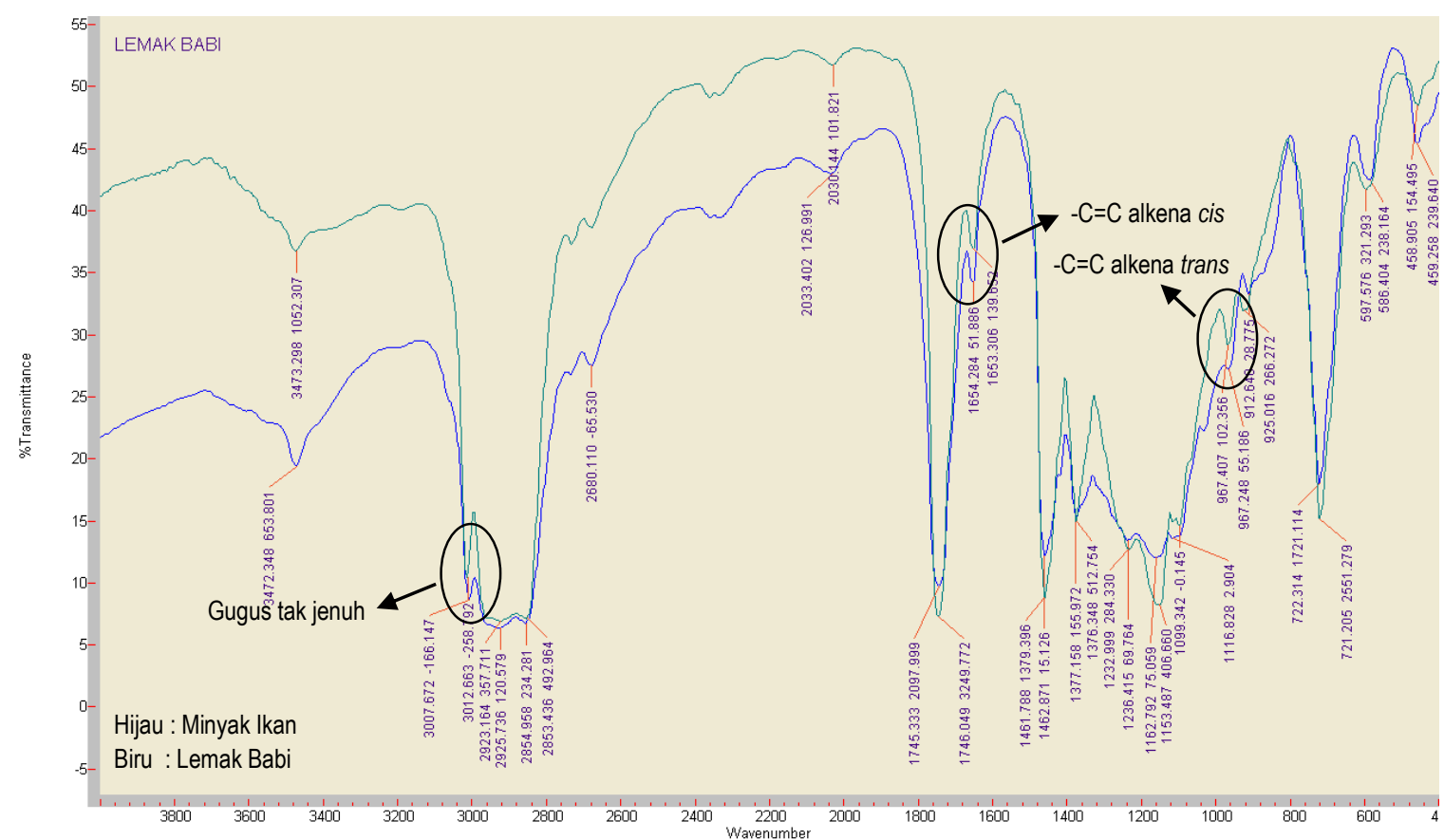

Gambar 7. Spektra IR gabungan hasil ekstraksi minyak ikan tuna dan lemak babi.

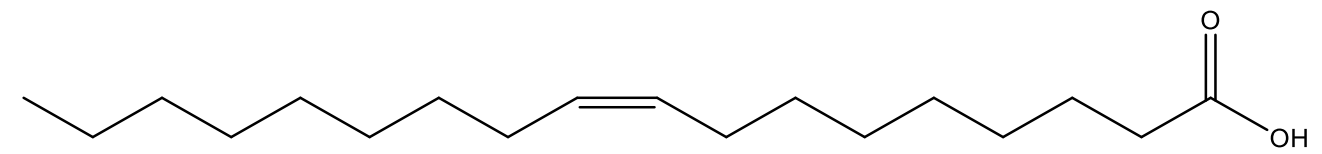

(a)

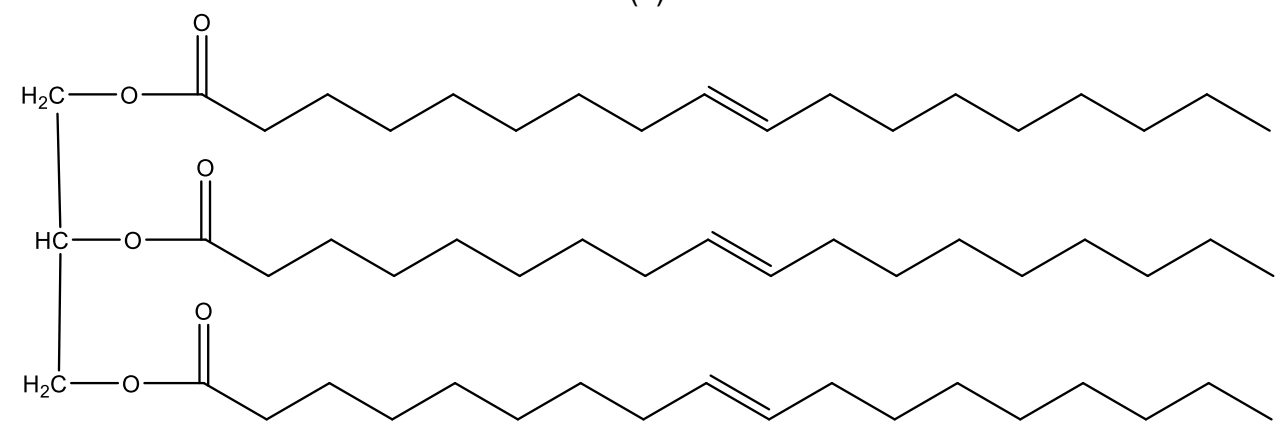

(b)

Gambar 8 (a) Struktur asam oleat (asam cis-9-oktadekenoat), dan (b) Trigliserida asam oleat.

Menurut penelitian Hermanto dkk. [5], lemak babi mengandung asam lemak tidak jenuh yang komposisinya lebih besar dibanding asam lemak jenuhnya, yaitu asam oleat sebesar $40,74 \%$ dan asam linoleat sebesar $24,94 \%$, sedangkan asam stearat sebesar 13,95\%. Hal ini diperkuat oleh hasil penelitian Jaswir dkk. [10], dimana untuk sampel lemak babi, kandungan asam lemak tidak jenuh ganda (PUFA) seperti asam linoleat dan asam linolenat jauh lebih besar daripada asam lemak jenuh tunggal (MUFA). Jadi, meskipun lemak babi maupun minyak ikan tuna sama-sama mempunyai kandungan asam oleat dengan komposisi yang tinggi, tetapi komposisi asam oleat dari minyak ikan tuna jauh lebih tinggi daripada lemak babi. Oleh karena itu, serapan pada minyak ikan tuna pada bilangan gelombang $3010-3000 \mathrm{~cm}^{-1}$ lebih tajam dibanding lemak babi. Struktur senyawa asam lemak tidak jenuh ditunjukkan pada Gambar 9.

Pola serapan pada bilangan gelombang $967 \mathrm{~cm}^{-1}$ untuk sampel minyak ikan menunjukkan puncak yang relatif tinggi jika dibandingkan dengan sampel lemak babi. Tingginya puncak serapan untuk minyak ikan pada daerah ini merepresentasikan streching vibration dari ikatan rangkap $\mathrm{C}=\mathrm{C}$ trans. Pada sampel lemak babi, terlihat ada puncak yang 
muncul pada daerah tersebut, tetapi intensitas serapannya sangat lemah. Perbedaan profil spektra IR lemak babi dan minyak ikan dapat digunakan untuk menentukan apakah suatu bahan atau produk tercampur lemak babi atau tidak. Walaupun harus juga dibandingkan dengan profil spektra IR bahan lain seperti daging ayam, daging kambing dan daging sapi sehingga bermanfaat untuk penentuan kehalahan suatu produk.

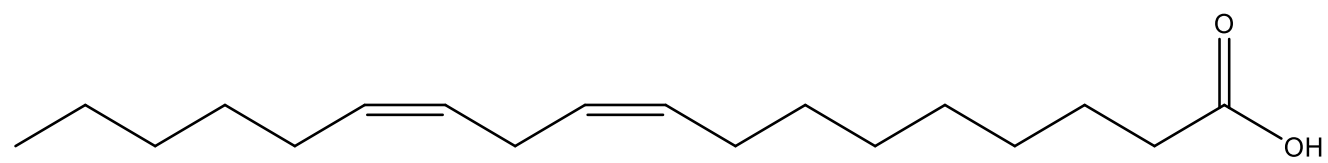

(a)

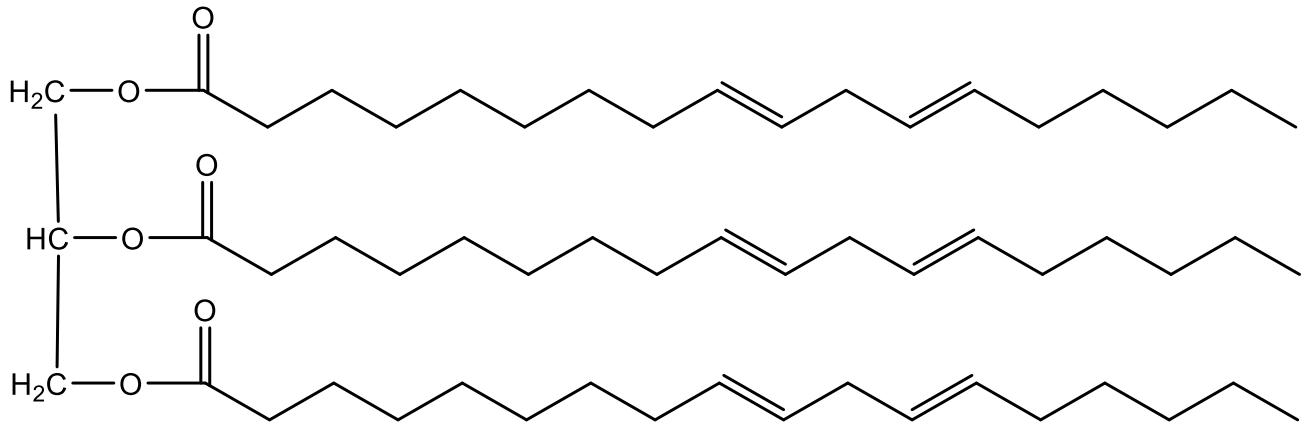

(b)<smiles>CCCCCCCCCCCCCCCCCC(=O)O</smiles>

(c)

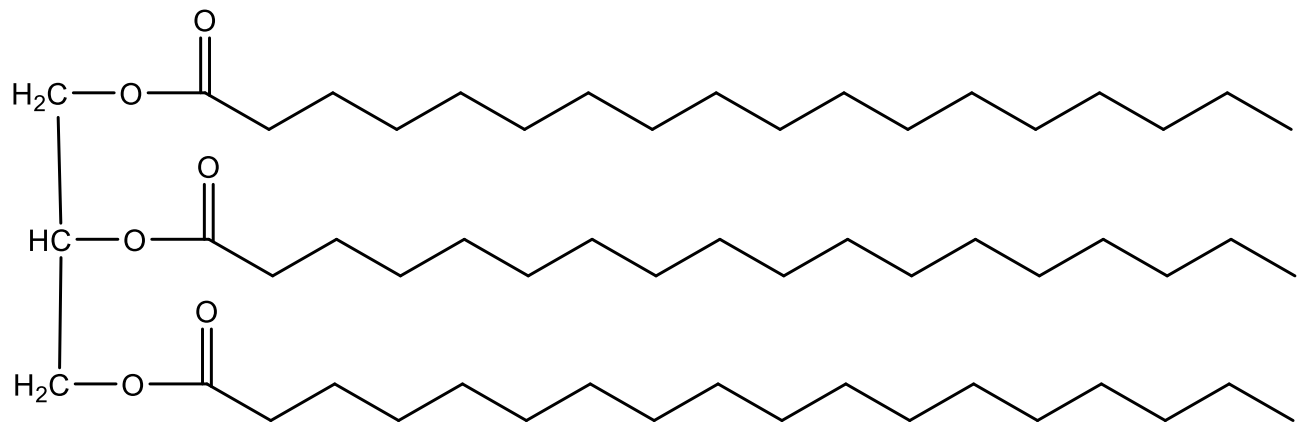

(d)

Gambar 9. (a) Struktur asam linoleat (asam cis, cis-9,12-Oktadekadienoat), (b) trigliserida asam linoleat, (c) Asam stearat (asam oktadekanoat), dan (d) Senyawa trigliserida dari asam stearat.

\section{Kesimpulan}

Profil asam lemak hasil analisis FTIR menunjukkan adanya perbedaan yang cukup signifikan pada pola-pola penyerapan spektra, khususnya pada bilangan gelombang 3010-3000, 1680-1600 dan 968-966 cm-1 yang merepresentasikan perbedaan komposisi dan jenis asam lemak pada sampel lemak babi dan minyak ikan tuna. Pola serapan pada bilangan gelombang 3007 dan $1653 \mathrm{~cm}^{-1}$ (ikatan rangkap $\mathrm{C}=\mathrm{C}$ cis) untuk sampel minyak ikan menunjukkan puncak yang relatif tinggi jika dibandingkan dengan sampel lemak babi karena persentase asam lemak MUFA (asam oleat) pada ikan tuna jauh lebih tinggi daripada pada lemak babi.

\section{Daftar Pustaka}

[1] A. G. Fasya, S. Amalia, M. Imamudin, R. P. Nugraha, M. Ni'mah, \& D. Yuliani, "Optimasi Produksi Gelatin Halal dari Tulang Ayam Broiler (Gallus domesticus) dengan Variasi Lama Perendaman dan Konsentrasi Asam Klorida (HCl)," Indonesian Journal of Halal, vol. 1, no.2, pp. 102-108, 2018.

[2] A. Rohman \& Y. B. Che Man, "Review Article: Analysis of Lard in Food Products for Halal Authentication Study," Agritech, vol. 28, pp. 192-201, 2008.

[3] A. Apriyantono, "Pengaruh Perkembangan Teknologi Pangan dalam Menentukan Status Kehalalan Produk Pangan," dalam Seminar Good Manufacturing Practices yang sesuai dengan Good Halal Practices, Jakarta, 2001. 
[4] N. Vlachos, Y. Skopelitis, M. Psaorudaki, V. Konstantinidou, A. Chatzilazarou, \& E. Tegou, "Application of Fourier Transform-Infrared Spectroscopy to Edible Oils," Analytica Chimica Acta, vol. 573-574, pp. 459-465, 2006.

[5] S. Hermanto, A. Muawanah, \& R. Harahap, "Profil dan Karakteristik Lemak Hewani (Ayam, Sapi dan Babi) Hasil Analisa FTIR dan GCMS," Jurnal Valensi, vol. 1, no. 3, pp. 102-109, 2008.

[6] Khamidinal, Teknik Laboratorium Kimia. Yogyakarta: Pustaka Pelajar, 2009.

[7] R. Crowley, The Chemistry and Analysis of Trans Fatty Acids, Food Product Design, Food Science Newsletter. New York: John Wiley \& Sons, 2006.

[8] J. M. De Man, Kimia Makanan, edisi kedua. Bandung: ITB Press, 1997.

[9] F. Defandi, "Sifat Fisiko Kimia Minyak Ikan dari Limbah Pengolahan Ikan Tuna (Thunnus sp.)," Skripsi, Universitas Andalas, Padang, 2015.

[10] I. Jaswir, M. E. S. Mirghani, T. H. Hassan, \& M. Z. M. Said, "Determination of Lard in Mixture of Body Fats of Mutton and Cow by Fourier Transform Infrared Spectroscopy," Journal of Oleo Science, vol. 52, no. 12, pp. 633-638, 2003. 